ARTÍCULO CIENTíFICO

\title{
Efectos de la suplementación de metionina, treonina y triptófano sobre el rendimiento productivo y la calidad de canal de los cerdos en crecimiento bajo condiciones comerciales de producción ${ }^{1 \mathrm{~A}}$
}

\author{
Sergio Salazar-Villanea ${ }^{42}$, Luis E. Conejo-Chacón ${ }^{3}$, Marco V. Martínez-Aguilar ${ }^{4}$, Cristian Gómez-Chaves ${ }^{5}$, \\ Sebastián Dorado-Montenegro ${ }^{46}$
}

\section{RESUMEN}

El objetivo de este experimento fue determinar si la suplementación de metionina, treonina y triptófano en la dieta de cerdos en crecimiento y engorde criados en condiciones comerciales mejora su rendimiento productivo (consumo de alimento, ganancia de peso, conversión alimenticia, calidad de canal) y si esta estrategia es viable económicamente. El experimento se desarrolló simultáneamente en dos granjas comerciales, con cerdos alimentados durante las etapas de inicio, desarrollo y engorde con una dieta control que cumplía con el perfil de proteína ideal o con una dieta suplementada con un $20 \%$ adicional de metionina, treonina y triptófano. No hubo diferencias $(P>0,05)$ en el consumo de alimento, ganancia de peso diaria o la conversión alimenticia entre los animales alimentados con la dieta control y la dieta suplementada en ninguna de las etapas productivas, ni cuando se analizó el ciclo completo. Tampoco hubo diferencias entre los animales alimentados con ambas dietas en el porcentaje de carne magra de la canal, en el precio que se pagó por kilogramo canalo el ingreso por animal. Los animales que consumieron la dieta suplementada presentaron una tendencia $(P=0,07)$ a tener un mayor espesor de grasa dorsal $(13,46 \mathrm{~mm})$ comparados con los animales control $(12,62 \mathrm{~mm})$. Además, los animales suplementados presentaron una tendencia $(P=0,08)$ a tener un mayor rendimiento en canal $(80,10 \%)$ comparados con los animales que consumieron la dieta control $(79,54 \%)$. Se concluye que la suplementación de metionina, treonina y triptófano no mejoró el rendimiento productivo de los cerdos en crecimiento bajo condiciones comerciales y en las condiciones actuales no es viable económicamente.

Palabras clave: aminoácidos, rendimiento productivo, cerdos.

\footnotetext{
A Universidad de Costa Rica, Escuela de Zootecnia y Centro de Investigación en Nutrición Animal. San José, Costa Rica. ${ }^{1}$ Proyecto de Investigación 739-B8-022, Vicerrectoría de Investigación. Este trabajo formó parte de la tesis de licenciatura del segundo y tercer autor.

2घ Autor para correspondencia: sergio.salazarvillanea@ucr.ac.cr. (https://orcid.org/0000-0002-0332-6263)

${ }^{3}$ Consultor independiente. Alajuela, Costa Rica. Correo electrónico: conejo.le.15@gmail.com.

${ }^{4}$ Granja Marina, Industrias Martec. Puntarenas, Costa Rica. Correo electrónico: marco mar93@hotmail.com.

${ }^{5}$ Vitaminas y Minerales S.A. Cartago, Costa Rica. Correo electrónico: cgomez@vymisa.com

${ }^{6}$ Correo electrónico: sebastian.dorado@ucr.ac.cr (https://orcid.org/0000-0002-9220-6318)

Recibido: 13 agosto $2020 \quad$ Aceptado: 07 octubre 2020

Esta obra está bajo licencia internacional CreativeCommons Reconocimiento-NoComercial-SinObrasDerivadas 4.0.
} 


\section{ABSTRACT}

Effects of methionine, threonine and tryptophan supplementation on productive performance and carcass traits of growing-finishing pigs raised under commercial conditions. The aim was to determine whether the supplementation of methionine, threonine and tryptophan in the diets of growing-finishing pigs raised under commercial conditions improved their productive performance (feed intake, weight gain, feed conversion rate, carcass quality) and whether this strategy was economically viable. The experiment was performed simultaneously in 2 commercial pig farms, with animals fed during their grower-finisher period $(30-100 \mathrm{~kg})$ with a diet that met their ideal protein requirement and a diet supplemented with an additional 20\% methionine, threonine and tryptophan. There were no effects $(P>0.05)$ of the diet on feed intake, average daily gain or feed conversion rate in any of the grower-finisher stages, or when the whole testing period was analyzed. Furthermore, there were no differences between diets for the lean meat percentage, the value for each kilogram of meat or the value of the whole carcass. The animals that consumed the supplemented diet showed a tendency $(P=0.07)$ to have a higher back fat thickness $(13.46 \mathrm{~mm})$ compared to those that were fed the control diet $(12.62 \mathrm{~mm})$. Moreover, the animals fed with the supplemented diet also showed a tendency $(P=0.08)$ to have a higher carcass yield (80.10\%) compared to the animals that consumed the control diet (79.54\%). It can be concluded that methionine, threonine and tryptophan supplementation did not improve the productive performance of pigs raised under commercial conditions and, under the current productive setup, is not economically viable.

Keywords: amino acids, performance, swine.

\section{INTRODUCCIÓN}

La activación del sistema inmune en granjas porcinas debido a problemas sanitarios puede provocar la reducción del consumo voluntario de alimento y de la ganancia diaria de peso de los animales. Sin embargo, se ha sugerido que la reducción en el crecimiento de los animales después de un desafío en el estado sanitario no es únicamente producto de la reducción del consumo voluntario de alimento, sino también producto del aumento en los requerimientos para los procesos digestivos y metabólicos (Sandberg, Emmans, \& Kyriazakis, 2007), especialmente relacionados con el sistema inmune. Un desafío en el estado sanitario de los animales podría modificar la partición de nutrientes, desde la deposición de tejido muscular hacia una respuesta metabólica en soporte de la función inmune (Pastorelli, van Milgen, Lovatto, \& Montagne, 2012). Asociado al desarrollo de una enfermedad (con síntomas clínicos o subclínicos) se da una reducción en la síntesis y un aumento en el catabolismo de proteína de origen muscular producto de la acción de las citoquinas (Klasing \& Johnstone, 1991). Los aminoácidos originados del 
catabolismo de proteína muscular son utilizados para la síntesis hepática de proteínas de fase aguda (Klasing, Johnstone, \& Benson, 1991), lo cual eleva los requerimientos de mantenimiento de ciertos aminoácidos.

Recientemente fue demostrado bajo condiciones experimentales que la suplementación de un $20 \%$ adicional de metionina, treonina y triptófano a dietas formuladas con base en el perfil de proteína ideal de los cerdos desde los 17 a $110 \mathrm{~kg}$ de peso vivo aumentó la ganancia de peso en $20 \mathrm{~g} /$ día en los animales criados con estados sanitarios deficientes y $44 \mathrm{~g} /$ día en los animales criados con estados sanitarios adecuados (van der Meer, Lammers, \& Jansman, 2016). En el mismo estudio, la conversión alimenticia de los cerdos criados en un estado sanitario deficiente y alimentados con dietas suplementadas fue de 2,08, mientras que en los cerdos alimentados con dietas basales fue de 2,17. En los cerdos con adecuado estado sanitario no se reportaron diferencias en la conversión alimenticia. Estos resultados, sin embargo, no han sido comprobados bajo condiciones comerciales de producción, donde es posible que la presión de agentes patológicos sea de mayor magnitud. La hipótesis de este ensayo es que bajo condiciones comerciales se obtendrán resultados similares a las condiciones experimentales descritas anteriormente, donde los cerdos suplementados con metionina, treonina y triptófano tengan rendimientos productivos superiores a aquellos alimentados con una dieta basal formulada a partir de un perfil de proteína ideal.

La metionina, a través de la conversión en otros productos (por ejemplo, homocisteína, betaína, colina, entre otros), interviene en los mecanismos de inflamación y en la síntesis de otros compuestos como acetilcolina y fosfoacetilcolina. El triptófano (entre otros mecanismos de acción relacionados a propiedades antiinflamatorias) es precursor de la serotonina (el cual es un neurotransmisor) y de la melatonina (antioxidante), los cuales inhiben la producción de citoquinas proinflamatorias. La treonina está directamente ligada a la proliferación de linfocitos y a la síntesis de mucina, la cual es necesaria para mantener la función inmune a nivel intestinal. El aumento en la producción de mucosidad durante el desarrollo de enfermedades eleva los requerimientos de este aminoácido (Li, Yin, Li, Kim, \& Wu, 2007). Por lo tanto, se espera que la suplementación de estos 3 aminoácidos en la dieta de cerdos en crecimiento bajo condiciones comerciales de producción incremente su rendimiento productivo, al satisfacer los requerimientos del sistema inmune y desfavorecer el catabolismo de proteína muscular. Los beneficios de la suplementación podrían ser mayores para granjas con estados sanitarios deficientes, donde existe una mayor presión de agentes patogénicos.

El objetivo de este experimento fue determinar si la suplementación de metionina, treonina y triptófano en la dieta de cerdos en condiciones comerciales mejora su rendimiento productivo y si esto era viable económicamente. Las mejoras en el rendimiento productivo podrían beneficiar 
a los productores y además reducir la excreción de nutrientes al medio ambiente al aumentar la retención de proteína.

\section{MATERIALES Y MÉTODOS}

El experimento se realizó de manera simultánea en dos granjas porcinas comerciales. La Granja 1, localizada en la provincia de Puntarenas, Costa Rica, cuenta con 270 vientres de línea materna York-Landrace y animales terminales de la línea genética Topigs-Norsvin. La Granja 2, localizada en la provincia de San José, Costa Rica, cuenta con alrededor de 300 vientres de la línea genética Choice Genetics.

Para el experimento se seleccionaron dos corrales por semana en cada granja, los cuales fueron asignadosa la dieta control y la dieta suplementada, respectivamente. Esto se repitió durante 4 semanas consecutivas hasta completar 4 repeticiones (4 corrales) por tratamiento en cada granja. Se consideró el corral como unidad experimental, con 50 animales por corral en la Granja 1 y 45 animales por corral en la Granja 2. El peso promedio de los animales en la Granja 1 al inicio del experimento fue de $26,8 \pm 2,6 \mathrm{~kg}$, mientras en la Granja 2 fue de 30,1 $\pm 3,2 \mathrm{~kg}$. El peso promedio de salida de los animales en la Granja 1 fue de 107,0 $\pm 6,2 \mathrm{~kg}$, mientras que en la Granja 2 fue de $100,8 \pm 6,9 \mathrm{~kg}$.

Las dietas utilizadas consistieron en una dieta control y otra suplementada con metionina, treonina y triptófano para las etapas de inicio, desarrollo y engorde, respectivamente, en cada una de las granjas (Cuadro 1). Las dietas fueron formuladas con base en una combinación de las tablas de requerimientos brasileñas (Rostagno et al., 2017), del National Research Council (2012) y de la casa comercial Topigs Norsvin (2016) tomando en cuenta los factores ambientales (clima, instalaciones) de las granjas. La dieta control que se utilizó fue la dieta propia de cada granja, que cumplía con el perfil de proteína ideal para cerdos en crecimiento (Ajinomoto, 2016). La dieta suplementada consistía en la suplementación de un $20 \%$ adicional de los aminoácidos metionina, treonina y triptófano a la dieta control en cada una de las granjas. Las dietas fueron formuladas para ser isoproteicas e isoenergéticas. En la Granja 1, se utilizó florfenicol (0,04 kg/ton) y clortetraciclina $(0,4 \mathrm{~kg} / \mathrm{ton})$ en ambas dietas experimentales durante la primera semana de las etapas de inicio y desarrollo. En la Granja 2, se utilizó florfenicol (0,8 kg/ton) y clortetraciclina (2 $\mathrm{kg} /$ ton) durante las dos primeras semanas de las etapas de inicio y desarrollo para ambas dietas experimentales. Además, durante las dos semanas restantes de las etapas de inicio y desarrollo y durante la totalidad de la etapa de engorde se utilizó bacitracina $(0,7 \mathrm{~kg} / \mathrm{ton})$ en ambas dietas experimentales. 
Los animales se pesaron individualmente al inicio del experimento cuando empezaron a consumir alimento iniciador y posteriormente en cada cambio de etapa (desarrollo y engorde). Para el peso final de los animales, se utilizaron los pesos reportados por la planta de procesamiento. El consumo de alimento se registró de forma diaria, anotando los sacos de alimento consumidos por cada corral. Para el cálculo de la conversión alimenticia se utilizó el consumo total de alimento y la ganancia de peso por etapa y durante todo el ciclo productivo (inicio - finalización). Las mediciones de calidad de canal (rendimiento en canal, espesor de grasa dorsal y porcentaje de carne magra) fueron suministradas por las plantas de procesamiento. Con el fin de uniformizar el valor económico de la canal de los animales experimentales (pues cada granja entregaba cerdos a una planta de cosecha distinta), se solicitó a una empresa nacional que se dedica a la comercialización de carne de cerdo que estimara el precio por kilogramo en canal, utilizando las mediciones de calidad de canal para los animales de ambas dietas y ambas granjas. Esos valores se utilizaron para estimar el valor de un cerdo de $100 \mathrm{~kg}$ de peso en pie para el análisis de costobeneficio de la utilización de la dieta suplementada.

Se realizó un análisis de varianza utilizando el PROC GLM del software estadístico SAS (Versión 9,2 SAS Institute Inc. 2011). El análisis se realizó para cada etapa de crecimiento (inicio, desarrollo y engorde) utilizando medidas repetidas y para los rendimientos productivos durante todo el ciclo (desde inicio hasta salida a matadero). En el modelo se incluyeron los efectos de granja y semana como bloques y el efecto principal del tratamiento (dieta). 
Cuadro 1. Composición y perfil nutricional calculado de las dietas experimentales para ambas granjas.

\begin{tabular}{|c|c|c|c|c|c|c|c|c|c|c|c|c|}
\hline \multirow[t]{3}{*}{ Ingrediente } & \multicolumn{6}{|c|}{ Granja 1} & \multicolumn{6}{|c|}{ Granja 2} \\
\hline & \multicolumn{2}{|c|}{ Inicio } & \multicolumn{2}{|c|}{ Desarrollo } & \multicolumn{2}{|c|}{ Engorde } & \multicolumn{2}{|c|}{ Inicio } & \multicolumn{2}{|c|}{ Desarrollo } & \multicolumn{2}{|c|}{ Engorde } \\
\hline & Control & Supl. & Control & Supl. & Control & Supl. & Control & Supl. & Control & Supl. & Control & Supl. \\
\hline Maíz amarillo & 68,4 & 68,6 & 72,8 & 73,0 & 70,6 & 70,8 & 70,6 & 70,8 & 71,9 & 73,1 & 71,6 & 71,8 \\
\hline Harina de soya & 26,1 & 25,6 & 21,8 & 21,3 & 25,0 & 24,5 & 25,0 & 24,5 & 23,6 & 22,0 & 24,0 & 23,6 \\
\hline Acemite & 1,0 & 1,0 & 1,5 & 1,5 & 1,0 & 1,0 & & & & & & \\
\hline Aceite de soya & 0,8 & 0,9 & 0,5 & 0,5 & 0,4 & 0,4 & & & & & & \\
\hline Aceite de palma & & & & & & & 0,6 & 0,7 & 1,0 & 1,0 & 1,0 & 1,0 \\
\hline Carbonato fino & 1,2 & 1,3 & 1,0 & 1,0 & 1,1 & 1,2 & 1,3 & 1,3 & 1,4 & 1,4 & 1,4 & 1,4 \\
\hline Sal & 0,4 & 0,4 & 0,4 & 0,4 & 0,4 & 0,4 & 0,4 & 0,4 & 0,4 & 0,4 & 0,4 & 0,4 \\
\hline Núcleo & 2,1 & 2,3 & 2,1 & 2,3 & 1,6 & 1,9 & 2,0 & 2,3 & 1,7 & 2,1 & 1,6 & 1,9 \\
\hline \multicolumn{13}{|c|}{ Composición nutricional calculada (\%) } \\
\hline Proteína cruda & 18,0 & 18,0 & 17,0 & 17,0 & 17,5 & 17,5 & 18,0 & 18,0 & 17,0 & 17,0 & 17,5 & 17,5 \\
\hline Extracto etéreo & 4,1 & 3,7 & 3,5 & 4,1 & 4,4 & 3,3 & 3,6 & 3,6 & 4,0 & 4,0 & 3,9 & 3,9 \\
\hline Fibra cruda & 2,9 & 2,9 & 2,9 & 2,8 & 2,9 & 2,9 & 2,9 & 2,9 & 2,8 & 2,8 & 2,8 & 2,8 \\
\hline Calcio & 0,8 & 0,8 & 0,7 & 0,7 & 0,7 & 0,7 & 0,8 & 0,8 & 0,8 & 0,8 & 0,8 & 0,8 \\
\hline Fósforo disponible & 0,4 & 0,4 & 0,3 & 0,3 & 0,3 & 0,3 & 0,4 & 0,4 & 0,3 & 0,3 & 0,3 & 0,3 \\
\hline EM (Mcal/kg) & 3,35 & 3,35 & 3,35 & 3,35 & 3,35 & 3,35 & 3,33 & 3,33 & 3,35 & 3,35 & 3,35 & 3,35 \\
\hline Lisina digestible & 1,21 & 1,21 & 1,15 & 1,15 & 1,10 & 1,10 & 1,23 & 1,23 & 1,17 & 1,17 & 1,13 & 1,13 \\
\hline Treonina digestible & 0,74 & 0,89 & 0,70 & 0,84 & 0,71 & 0,84 & 0,76 & 0,92 & 0,71 & 0,88 & 0,72 & 0,85 \\
\hline Metionina digestible & 0,43 & 0,50 & 0,40 & 0,50 & 0,33 & 0,43 & 0,36 & 0,52 & 0,36 & 0,50 & 0,42 & 0,49 \\
\hline Triptófano digestible & 0,19 & 0,24 & 0,17 & 0,20 & 0,19 & 0,23 & 0,19 & 0,23 & 0,19 & 0,22 & 0,18 & 0,22 \\
\hline
\end{tabular}

Abreviaciones: Supl., suplementadas; EM, energía metabolizable. 


\section{RESULTADOS Y DISCUSIÓN}

En el Cuadro 2 se pueden observar los rendimientos productivos por etapa de los animales alimentados con la dieta control y suplementada con un $20 \%$ adicional de los aminoácidos metionina, treonina y triptófano.

No se observaron diferencias $(P>0,05)$ en el consumo diario de alimento, la ganancia diaria de peso o la conversión alimenticia entre los animales que consumieron la dieta control y la dieta suplementada con un $20 \%$ adicional de los aminoácidos metionina, treonina y triptófano para ninguna de las etapas incluidas en la prueba.

Estudios anteriores desarrollados bajo condiciones experimentales (Pastorelli et al., 2012; van der Meer et al., 2016) demostraron que la suplementación de estos tres aminoácidos en la dieta de animales con y sin desafío sanitario mejoró el rendimiento productivo de los animales. Una posible razón para las diferencias encontradas con los resultados reportados en la literatura podría ser un mayor desafío sanitario de los animales utilizados bajo condiciones experimentales, ya que los animales utilizados en el presente experimento bajo condiciones comerciales recibieron antimicrobianos en el alimento, utilizados como promotores de crecimiento (esto es, sin evidencia clínica de enfermedad de los animales), lo cual podría haber limitado cualquier reto inmunológico de los animales bajo un esquema de producción intensiva comercial. Los antimicrobianos utilizados como promotores de crecimiento tienen un efecto en el control, la reducción de la incidencia y la severidad de infecciones subclínicas en animales en crecimiento (Ardoino et al., 2017). Esto minimiza la producción de citoquinas liberadas durante el proceso inmune, lo cual previene la estimulación y liberación de hormonas catabólicas que aumentan el catabolismo de proteínas musculares (Humphrey \& Klasing, 2004).

Además, la edad de los animales podría ocasionar diferencias entre los resultados reportados en la presente investigación en comparación con la literatura. En algunos estudios previos con resultados positivos de la suplementación de aminoácidos se utilizaron animales entre el destete (cerca de la cuarta semana de vida) y la décima u onceava semana de vida (Le Floc'h, Lebellego, Matte, Melchior, \& Sève, 2009; Pastorelli et al., 2012). En otros estudios, en los que se utilizaron animales con pesos similares a los utilizados en el presente experimento, se reportó una tendencia a una mayor ganancia de peso durante el período de inicio en los animales que fueron suplementados comparados con aquellos que consumieron la dieta control, pero esta tendencia desapareció durante los periodos de desarrollo y engorde (van der Meer et al., 2016). Los animales alcanzan la inmunocompetencia adulta entre la séptima y la novena semana de vida (Potočnjak et al., 2012), lo cual podría explicar que haya un efecto 
mayor de la suplementación de aminoácidos en animales jóvenes comparados con animales de mayor edad.

Cuadro 2. Rendimiento productivo de los cerdos en las etapas de inicio, desarrollo y engorde alimentados con la dieta control y la dieta suplementada con $20 \%$ adicional de metionina, treonina y triptófano.

\begin{tabular}{|c|c|c|c|c|}
\hline \multirow[t]{2}{*}{ Parámetro productivo por etapa } & \multicolumn{2}{|r|}{ Dieta } & \multirow[t]{2}{*}{ Error estándar } & \multirow[t]{2}{*}{ Valor $P$} \\
\hline & Control & Suplementada & & \\
\hline \multicolumn{5}{|l|}{ Inicio } \\
\hline CDA $(\mathrm{kg} / \mathrm{d})$ & 1,81 & 1,80 & 0,03 & 0,84 \\
\hline GDP $(\mathrm{kg} / \mathrm{d})$ & 0,83 & 0,84 & 0,01 & 0,62 \\
\hline CA & 2,18 & 2,16 & 0,05 & 0,70 \\
\hline \multicolumn{5}{|l|}{ Desarrollo } \\
\hline CDA $(\mathrm{kg} / \mathrm{d})$ & 2,26 & 2,27 & 0,04 & 0,87 \\
\hline GDP $(k g / d)$ & 0,97 & 0,97 & 0,02 & 0,85 \\
\hline CA & 2,35 & 2,37 & 0,04 & 0,75 \\
\hline \multicolumn{5}{|l|}{ Engorde } \\
\hline CDA $(\mathrm{kg} / \mathrm{d})$ & 2,47 & 2,45 & 0,05 & 0,79 \\
\hline GDP $(\mathrm{kg} / \mathrm{d})$ & 0,81 & 0,79 & 0,03 & 0,61 \\
\hline CA & 3,12 & 3,12 & 0,10 & 0,97 \\
\hline \multicolumn{5}{|c|}{$\begin{array}{l}\text { Abreviaciones: CDA, consumo diario de alimento; GDP, ganancia diaria de peso; CA, conversión } \\
\text { alimenticia. }\end{array}$} \\
\hline \multicolumn{5}{|c|}{$\begin{array}{l}\text { Cuando se analizó todo el ciclo de crecimiento, tampoco se observaron diferencias }(P>0,05) \\
\text { en el consumo diario de alimento, la ganancia diaria de peso o la conversión alimenticia entre } \\
\text { los animales alimentados con las dietas control y suplementada con } 20 \% \text { extra de metionina, } \\
\text { treonina y triptófano (Cuadro 3). }\end{array}$} \\
\hline \multicolumn{5}{|c|}{$\begin{array}{l}\text { En cuanto a las características de canal, no hubo diferencias }(P>0,05) \text { entre los animales } \\
\text { alimentados con las dietas control y suplementadas para el porcentaje de carne magra, el } \\
\text { precio pagado por kilogramo en canal y el ingreso por animal. En contraste, hubo una } \\
\text { tendencia }(P=0,07) \text { a que los animales alimentados con la dieta suplementada presentaran un } \\
\text { mayor grosor de grasa dorsal }(13,46 \mathrm{~mm}) \text { comparados con aquellos alimentados con la dieta } \\
\text { control }(12,62 \mathrm{~mm}) \text {. Además, hubo una tendencia ( } P=0,08) \text { a que los animales suplementados } \\
\text { con los aminoácidos tuvieran un rendimiento en canal superior comparado con aquellos que } \\
\text { consumieron la dieta control }(80,10 \text { y } 79,54 \% \text {, respectivamente). }\end{array}$} \\
\hline
\end{tabular}


Cuadro 3. Rendimiento productivo en todo el ciclo de prueba y características de canal de los animales alimentados con la dieta control y suplementada con $20 \%$ adicional de metionina, treonina y triptófano.

\begin{tabular}{|c|c|c|c|c|}
\hline \multirow[t]{2}{*}{ Parámetro } & \multicolumn{2}{|c|}{ Dieta } & \multirow[t]{2}{*}{ Error estándar } & \multirow[t]{2}{*}{ Valor $P$} \\
\hline & Control & Suplementada & & \\
\hline \multicolumn{5}{|l|}{ Características productivas } \\
\hline CDA $(k g / d)$ & 2,17 & 2,18 & 0,03 & 0,79 \\
\hline GDP $(k g / d)$ & 0,86 & 0,86 & 0,01 & 0,65 \\
\hline CA & 2,54 & 2,53 & 0,03 & 0,84 \\
\hline \multicolumn{5}{|l|}{ Características de canal } \\
\hline Carne magra (\%) & 57,82 & 57,44 & 0,20 & 0,16 \\
\hline Grasa dorsal (mm) & 12,62 & 13,46 & 0,30 & 0,07 \\
\hline Rendimiento en canal (\%) & 79,54 & 80,10 & 0,21 & 0,08 \\
\hline Precio por kg canal $(\mathbb{L})$ & 1545,48 & 1538,13 & 4,25 & 0,25 \\
\hline Ingreso por animal $(\mathbb{C})$ & $122.928,88$ & $123.208,88$ & 389,26 & 0,62 \\
\hline
\end{tabular}

Abreviaciones: CDA, consumo diario de alimento; GDP, ganancia diaria de peso; CA, conversión alimenticia. Tipo de cambio de referencia: 603,96 colones por dólar (al 7 de octubre 2020).

Los resultados obtenidos en grasa dorsal podrían deberse a un exceso de aminoácidos en los cerdos que consumieron la dieta suplementada por encima de su requerimiento, los cuales podrían haber sido catabolizados y utilizados como fuente de energía. Los aminoácidos pueden incorporarse en el Ciclo de Krebs y tener función glucogénica (metionina y treonina) o en el caso del triptófano puede tener función glucogénica o cetogénica (Bender, 2008). Ambas dietas fueron formuladas de manera que fueran isocalóricas por lo cual los resultados en grasa dorsal no podrían atribuirse a una mayor densidad energética de la dieta suplementada, sino al exceso de glucosa proveniente del catabolismo de los aminoácidos los cuales se metabolizan en la producción de ácidos grasos y se depositan como grasa dorsal. Lo anterior podría ser resultado de animales que no fueron retados inmunológicamente, posiblemente debido a la utilización de los antimicrobianos como promotores de crecimiento en las dietas.

La tendencia a que los animales suplementados presentaran valores superiores de rendimiento en canal resulta difícil de justificar, pero se podría deber al mayor espesor de grasa dorsal en estos animales, lo cual tiene un efecto positivo en el ingreso bruto por cerdo, que fue superior en los animales suplementados aún y cuando el pago por kilogramo en canal de estos animales fue menor (Cuadro 4). 
Cuadro 4. Ingreso neto calculado a partir de las características de canal y el costo de alimentar a los cerdos con la dieta control y la dieta suplementada.

\begin{tabular}{lcc}
\hline Parámetro & Control & Suplementada \\
\hline Peso canal $(\mathrm{kg})$ & 79,54 & 80,10 \\
Pago / kg canal $(\mathbb{C})$ & 1545,48 & 1538,13 \\
Ingreso bruto / cerdo $(\mathbb{C})$ & 122.929 & 123.209 \\
Costo alimenticio $(\mathbb{C})$ & 40.934 & 43.337 \\
Ingreso neto $(\mathbb{W})$ & 81.995 & 79.872 \\
\hline
\end{tabular}

Tipo de cambio de referencia: 603,96 colones por dólar (al 7 de octubre 2020).

En promedio para los cerdos criados en ambas granjas, el ingreso (diferencia entre el ingreso bruto por cerdo y el costo alimenticio) por cerdo fue $\mathbb{\$} 2.123$ superior en los cerdos alimentados con la dieta control en comparación con los cerdos alimentados con las dietas tratamiento.

Los resultados del presente experimento no coinciden con la hipótesis planteada. Se sugiere que no existe suficiente desafío sanitario en los animales debido a la utilización de antibióticos promotores de crecimiento en las dietas, por lo cual no se observaron efectos de la suplementación de aminoácidos. Sin embargo, dentro del contexto de la generación de resistencia a los antimicrobianos debido a un uso inadecuado (por ejemplo, como promotores de crecimiento) existe una tendencia a nivel mundial de limitar y disminuir su utilización, por lo cual sugerimos que esta estrategia nutricional (suplementación de aminoácidos para cubrir las necesidades del sistema inmune) se debería evaluar nuevamente en condiciones donde no se utilicen antibióticos de forma rutinaria como promotores de crecimiento y, por lo tanto, los animales estén expuestos a un mayor reto sanitario.

\section{CONSIDERACIONES FINALES}

En conclusión, la suplementación de metionina, treonina y triptófano no mejoró el rendimiento productivo de los cerdos en crecimiento bajo condiciones comerciales de producción y, en estas condiciones, la suplementación de estos aminoácidos no resulta económicamente viable.

\section{AGRADECIMIENTOS}

Los autores agradecen profundamente la colaboración de la empresa Vitaminas y Minerales S.A. y de los productores porcinos que facilitaron sus granjas para la ejecución de la prueba. 


\section{LITERATURA CITADA}

Ajinomoto. (2016). Ideal amino acid profile and low crude protein diets for fattening pigs. Ajinomoto Animal Nutrition Group, Ajinomoto Eurolysine S.A.S., (June), 32.

Ardoino, S. M., Toso, R. E., Toribio, M. S., Álvarez, H. L., Mariani, E. L., Cachau, P. D., \& Oriani, D. S. (2017). Antimicrobianos como promotores de crecimiento (AGP) en alimentos balanceados para aves: uso, resistencia bacteriana, nuevas alternativas y opciones de reemplazo. Ciencia Veterinaria, 19(1), 50-66.

Bender, D. A. (2008). Introduction to nutrition and metabolism (4th Editio; C. Press, Ed.). Boca Raton, FL: Taylor \& Francis.

Humphrey, B. D., \& Klasing, K. C. (2004). Modulation of nutrient metabolism and homeostasis by the immune system. World's Poultry Science Journal, 601), 90-100. https://doi.org/DOI: 10.1079/WPS20037

Klasing, K. C., \& Johnstone, B. J. (1991). Monokines in growth and development. Poultry science, 708), 1781-1789. https://doi.org/10.3382/ps.0701781

Klasing, K. C., Johnstone, B. J., \& Benson, B. N. (1991). Implications of an immune response on growth and nutrient requirements of chicks. En W. Haresign \& D. J. A. B. T.-R. A. in A. N. Cole (Eds.), Studies in the Agricultural and Food Sciences (pp. 135-146). https://doi.org/https://doi.org/10.1016/B978-0-7506-1397-2.50012-5

Le Floc'h, N., Lebellego, L., Matte, J. J., Melchior, D., \& Sève, B. (2009). The effect of sanitary status degradation and dietary tryptophan content on growth rate and tryptophan metabolism in weaning pigs. Journal of Animal Science, 875), 1686-1694. https://doi.org/10.2527/jas.2008-1348

Li, P., Yin, Y.-L., Li, D., Kim, S. W., \& Wu, G. (2007). Amino acids and immune function. The British Journal of Nutrition, 98(2), 237-252. https://doi.org/10.1017/S000711450769936X

National Research Council. (2012). Nutrient requirements of swine (11th rev.; L. Southern, O. Adeola, C. F. M. De Lange, G. Hill, B. Kerr, M. Lindemann, ... N. Trottier, Eds.). Washington DC, Estados Unidos: National Academies Press.

Pastorelli, H., van Milgen, J., Lovatto, P., \& Montagne, L. (2012). Meta-analysis of feed intake and growth responses of growing pigs after a sanitary challenge. Animal, 6(06), 952-961. https://doi.org/10.1017/S175173111100228X 
Potočnjak, D., Kezić, D., Popović, M., Zdolec, N., Valpotić, H., Benković, V.,\&Valpotić, I. (2012). Age-related changes in porcine humoral and cellular immune parameters. Veterinarski Arhiv, 82(2), 167-181.

Rostagno, H., Teixeira Albino, L., Hannas, M., Lopes Donzele, J., Sakomura, N., Perazzo, F., \&de Oliveira Brito, C. (2017). Tablas brasileñas para aves y cerdos: composición de alimentos y requerimientos nutricionales. En H. Rostagno (Ed.), Departamento de Zootecnia, Universidad Federal de Viçosa (Vol. 4). Viçosa, Brasil.

Sandberg, F. B., Emmans, G. C., \& Kyriazakis, I. (2007). The effects of pathogen challenges on the performance of naïve and immune animals: the problem of prediction. Animal, $7($ May), 67. https://doi.org/10.1017/S175173110765784X

Topigs Norsvin. (2016). Feeding manual Norsvin Duroc progeny (p. 17). p. 17.

van der Meer, Y., Lammers, A., \& Jansman, A. J. M. (2016). Performance of pigs kept under different sanitary conditions affected by protein intake and amino acid supplementation. Journal of Animal Science, 94, 4704-4719. https://doi.org/10.2527/jas2016-0787 